\title{
Six2 Plays an Intrinsic Role in Regulating Proliferation of Mesenchymal Cells in the Developing Palate
}

\author{
Dennis O. Okello ${ }^{1 \dagger}$, Paul P. R. Iyyanar ${ }^{1 \dagger}$, William M. Kulyk ${ }^{2 \star}$, Tara M. Smith ${ }^{1,3}$, \\ Scott Lozanoff ${ }^{4}$, Shaoping $\mathrm{Ji}^{1,5}$ and Adil J. Nazarali ${ }^{1 \neq}$ \\ ${ }^{1}$ Laboratory of Molecular Cell Biology, Neuroscience Research Cluster, College of Pharmacy and Nutrition, University of \\ Saskatchewan, Saskatoon, SK, Canada, ${ }^{2}$ Department of Anatomy and Cell Biology, College of Medicine, University of \\ Saskatchewan, Saskatoon, SK, Canada, ${ }^{3}$ Med-life Discoveries LP, Saskatoon, SK, Canada, ${ }^{4}$ Department of Anatomy, \\ Biochemistry and Physiology, John A. Burns School of Medicine, University of Hawaii, Honolulu, HI, United States, \\ ${ }^{5}$ Department of Biochemistry and Molecular Biology, Medical School, Henan University, Kaifeng, China
}

OPEN ACCESS

Edited by:

David P. Rice,

University of Helsinki, Finland

Reviewed by:

Amel Gritli-Linde,

University of Gothenburg, Sweden

Frank Wagener,

Radboud Institute for Molecular Life

Sciences, Netherlands

${ }^{*}$ Correspondence:

William M. Kulyk

william.kulyk@usask.ca

${ }^{\dagger}$ These authors have contributed equally to this work.

${ }^{\ddagger}$ Passed away on April 27, 2017.

Specialty section:

This article was submitted to Craniofacial Biology and Dental

Research,

a section of the journal

Frontiers in Physiology

Received: 21 September 2017 Accepted: 09 November 2017 Published: 23 November 2017

Citation:

Okello DO, lyyanar PPR, Kulyk WM,

Smith TM, Lozanoff S, Ji S and

Nazarali AJ (2017) Six2 Plays an

Intrinsic Role in Regulating

Proliferation of Mesenchymal Cells in

the Developing Palate.

Front. Physiol. 8:955.

doi: 10.3389/fphys.2017.00955
Cleft palate is a common congenital abnormality that results from defective secondary palate (SP) formation. The Sine oculis-related homeobox 2 (Six2) gene has been linked to abnormalities of craniofacial and kidney development. Our current study examined, for the first time, the specific role of Six2 in embryonic mouse SP development. Six2 mRNA and protein expression were identified in the palatal shelves from embryonic days (E)12.5 to E15.5, with peak levels during early stages of palatal shelf outgrowth. Immunohistochemical staining $(\mathrm{IHC})$ showed that Six2 protein is abundant throughout the mesenchyme in the oral half of each palatal shelf, whereas there is a pronounced decline in Six2 expression by mesenchyme cells in the nasal half of the palatal shelf by stages E14.5-15.5. An opposite pattern was observed in the surface epithelium of the palatal shelf. Six2 expression was prominent at all stages in the epithelial cell layer located on the nasal side of each palatal shelf but absent from the epithelium located on the oral side of the palatal shelf. Six2 is a putative downstream target of transcription factor Hoxa2 and we previously demonstrated that Hoxa2 plays an intrinsic role in embryonic palate formation. We therefore investigated whether Six2 expression was altered in the developing SP of Hoxa2 null mice. Reverse transcriptase PCR and Western blot analyses revealed that Six2 mRNA and protein levels were upregulated in Hoxa2 ${ }^{-1-}$ palatal shelves at stages E12.5-14.5. Moreover, the domain of Six2 protein expression in the palatal mesenchyme of Hoxa2 ${ }^{-/-}$embryos was expanded to include the entire nasal half of the palatal shelf in addition to the oral half. The palatal shelves of Hoxa2 ${ }^{-/-}$ embryos displayed a higher density of proliferating, Ki-67 positive palatal mesenchyme cells, as well as a higher density of Six2/Ki-67 double-positive cells. Furthermore, Hoxa2 $^{-/-}$palatal mesenchyme cells in culture displayed both increased proliferation and elevated Cyclin D1 expression relative to wild-type cultures. Conversely, siRNA-mediated Six2 knockdown restored proliferation and Cyclin D1 expression in Hoxa2 ${ }^{-1-}$ palatal mesenchyme cultures to near wild-type levels. Our findings demonstrate that Six2 functions downstream of Hoxa2 as a positive regulator of mesenchymal cell proliferation during SP development.

Keywords: Six2, palate, Hoxa2, craniofacial development, cell proliferation, Cyclin D1 


\section{INTRODUCTION}

Cleft palate is a common congenital malformation in humans, with a complex etiology (Vanderas, 1987). The palate separates the nasal and oral cavities, allowing for proper respiration, feeding and phonation. Both genetic and environmental factors have been implicated in the causation of cleft palate (Dixon et al., 2011). However, the molecular mechanisms involved in the pathogenesis of cleft palate are poorly understood.

Mouse secondary palate (SP) development begins around embryonic day (E) 11.5, with the emergence of paired palatal shelf outgrowths from the maxillary prominences. From E12.0-13.5, the palatal shelves grow vertically downwards on either side of the developing tongue. At E14.0, the tongue depresses, allowing the two palatal shelves to re-orient horizontally above the tongue. The elevated palatal shelves grow horizontally toward each other, establishing contact to form the midline epithelial seam (MES) at E14.5. The MES degrades by E15.5, creating a confluent SP. The SP then fuses anteriorly with the primary palate, a derivative of the converged medial nasal processes, to complete the formation of the roof of the oral cavity by E16.5 (Ferguson, 1988; Kaufman, 1992). In addition, mesenchymal cells located in the anterior portion of the SP ossify to form the palatine bone. Disruptions in the growth, elevation or fusion of the palatal shelves can lead to congenital cleft palate defects (Ferguson, 1988; Gritli-Linde, 2007; Smith et al., 2013).

Sine oculis-related homeobox 2 (Six2) is a member of the vertebrate Six gene family which encode homeobox transcription factors homologous to the Drosophila Sine oculis protein (Kawakami et al., 2000). Six family genes have been reported to promote cell proliferation and survival during embryogenesis (Kawakami et al., 2000). Six2 is expressed primarily in the cranial base, midface, facial prominences, first pharyngeal arch, and in the urogenital region of the developing embryo (Fogelgren et al., 2008). Six2 null mice die at birth exhibiting renal hypoplasia (Self et al., 2006) and a shorter cranial base (He et al., 2010). In these mice, chondrocyte differentiation in the cranial base is abnormal, with decreased cell proliferation and increased terminal differentiation leading to premature fusion of the cranial base (He et al., 2010).

Downregulation of Six 2 by microRNAs miR-181b or miR$181 \mathrm{c}$ inhibits cell proliferation and promotes apoptosis in metanephric kidney mesenchymal cells in vitro (Lyu et al., 2013; Lv et al., 2014). Transcription factor Zeb1, a marker of epithelial-mesenchymal transitions during embryogenesis and cancer metastasis, regulates cell proliferation in metanephric mesenchymal cells by binding to the Six 2 promoter and upregulating its expression ( $\mathrm{Gu}$ et al., 2016). Additionally, Six2 promotes metastasis of breast cancer cells by repressing E-cadherin expression via mechanisms involving miR-200b downregulation, Zeb 2 upregulation, and E-cadherin promoter methylation (Wang et al., 2014).

Abbreviations: ddPCR, digital droplet PCR; E, embryonic day; IHC, immunohistochemical; MEE, medial edge epithelium; MEPM, mouse embryonic palatal mesenchyme; MES, midline epithelial seam; O-N, oro-nasal, qRT-PCR, quantitative real-time PCR; SP, secondary palate.
In the radiation-induced mouse mutant brachyrrhine $(\mathrm{Br} / \mathrm{Br})$, prenatal deficiency of Six2 leads to frontonasal dysplasia, cleft palate (Singh et al., 1998; McBratney et al., 2003) and renal hypoplasia (McBratney et al., 2003; Fogelgren et al., 2008, 2009). Moreover, investigations have linked Six2 deletion in humans to an autosomal dominant frontonasal dysplasia syndrome that has similarities to the murine $\mathrm{Br}$ mutant phenotype (Hufnagel et al., 2016).

Deletions of the Hoxa2 gene in mice also lead to cleft palate defects, together with altered morphogenesis of second pharyngeal arch structures (Rijli et al., 1993 and GendronMaguire et al., 1993). Investigations in our laboratory have previously demonstrated that Hoxa2 is expressed intrinsically within the palatal shelves of wild-type mouse embryos (Nazarali et al., 2000), where it inhibits proliferation of the palatal mesenchyme cells (Smith et al., 2009). The possibility that Six2 plays a specific role in SP development has not been previously examined. In our present study we demonstrate, for the first time, that Six2 is expressed intrinsically in both the palatal shelf mesenchyme and palatal shelf epithelium of wild-type mouse embryos, and further show that Six 2 mRNA and protein are upregulated in the palatal shelves of $\mathrm{Hoxa}^{-/-}$mice. In addition, we provide evidence that Six 2 functions downstream of Hoxa2 to regulate mesenchymal cell proliferation within the developing secondary palate.

\section{MATERIALS AND METHODS}

\section{Hoxa2 Transgenic Mice}

Hoxa $2^{+/-}$mice were maintained by backcrossing to C57BL/6J wild-type mice and the heterozygous mice were intercrossed to generate Hoxa2 $2^{+/+}$and Hoxa2 $2^{-/-}$embryos for analysis in this study (Smith et al., 2009). Pregnant mice were sacrificed by isoflurane inhalation followed by cervical dislocation. Embryos were staged according to Kaufman (1992) and were considered E0 on the day the vaginal plug was found. Genotypes were confirmed by PCR analyses as described in Gendron-Maguire et al. ( 1993). The protocol for the use of animals was approved by the University of Saskatchewan's Animal Research Ethics Board and adhered to Canadian Council on Animal Care guidelines for humane animal use.

\section{Immunohistochemistry}

Embryos were harvested from timed-pregnant mice and the heads were fixed with $4 \%$ paraformaldehyde in phosphate buffered saline, pH 7.4 (PBS) for $24 \mathrm{~h}$. Embryo heads were placed in $30 \%$ sucrose in PBS for at least $24 \mathrm{~h}$, followed by embedding in optimal cutting temperature compound (OCT; Tissue-Tek ${ }^{\circledR}$ ) and serially sectioned at $10 \mu \mathrm{m}$ thickness. Histological sections taken anterior or posterior to the first molar tooth bud were designated as anterior and posterior palate sections, respectively, and sections taken at the plane of the first molar tooth bud were designated as middle palate sections (Welsh and O'Brien, 2009; Smith et al., 2013). Tissue sections were placed on $0.5 \%$ gelatincoated glass slides, air-dried at room temperature for at least $2 \mathrm{~h}$, rehydrated for $30 \mathrm{~min}$ in $\mathrm{PBS}$, and blocked for $30 \mathrm{~min}$ at room temperature in PBS containing 4\% skim milk and $0.1 \%$ 
Triton X-100. Sections were then incubated overnight at $4^{\circ} \mathrm{C}$ with primary antibody diluted in PBS. The antibodies used were: Six2 rabbit polyclonal antibody (Proteintech ${ }^{\circledR} ; 1: 500$ dilution), E-cadherin rat monoclonal antibody (Sigma; 1:200 dilution) and Ki-67 rat monoclonal antibody (Affymetrix eBioscience ${ }^{\circledR} ; 1: 100$ dilution). Sections were rinsed twice for $5 \mathrm{~min}$ in PBS followed by incubation with secondary antibody for $1 \mathrm{~h}$ at room temperature (anti-IgG Alexa fluor 488 antibody, 1:200 dilution or anti-IgG Alexa fluor 594, 1:400 dilution; Molecular Probes ${ }^{\circledR}$ ). Finally, sections were rinsed twice in PBS and mounted in ProLong ${ }^{\circledR}$ Gold antifade reagent with DAPI (Molecular Probes ${ }^{\circledR}$ ).

\section{RNA Isolation and Reverse Transcription}

Total RNA was isolated from excised palatal shelves of wildtype and Hoxa2 ${ }^{-/-}$embryos at stages E12.5, E13.5, E14.5, and E15.5 using Aurum Total RNA mini kit (BioRad ${ }^{\circledR}$ ) as per the manufacturer's protocol. First-strand cDNA synthesis was performed using SuperScript reverse transcriptase (Invitrogen ${ }^{\circledR}$ ) with $1 \mu \mathrm{g}$ of total RNA as per the manufacturer's protocol (Smith et al., 2009).

\section{Quantitative Real Time PCR (qRT-PCR)}

Gene expression analysis was performed on palatal shelf cDNA samples as described in our previous study (Thangaraj et al., 2017). Briefly, a TaqMan ${ }^{\circledR}$ gene expression assay was used for qRT-PCR analysis of relative Six 2 mRNA expression levels. All qRT-PCR reactions were performed using $25 \mathrm{ng}$ of template cDNA, TaqMan Universal Master Mix, FAMlabeled TaqMan Gene Expression assay Mm03003557_S1 for Six2 (Applied Biosystems ${ }^{\circledR}$ ), and VIC-labeled endogenous control TaqMan assay for $\beta$-actin (Applied Biosystems ${ }^{\circledR}$ assay 4352341E). Cyclin D1 expression was quantified by SYBR Green assay using forward primer $5^{\prime}$-ACCCTGACACCAATCTCCTC$3^{\prime}$ and reverse primer $5^{\prime}$-AAGCGGTCCAGGTAGTTCAT-3'. All reactions were run in biological replicates of 5 . Thermocycling parameters were: $2 \mathrm{~min}$ at $50^{\circ} \mathrm{C}, 10 \mathrm{~min}$ at $95^{\circ} \mathrm{C}$, followed by 40 cycles of $95^{\circ} \mathrm{C}$ for $15 \mathrm{~s}$ and $60^{\circ} \mathrm{C}$ for $70 \mathrm{~s}$. The $\mathrm{C}_{\mathrm{T}}$ values obtained were analyzed using the $2^{-\Delta \Delta C T}$ method to determine the relative expression of target genes in wild-type and Hoxa2 null samples.

\section{Droplet Digital PCR (ddPCR)}

To independently confirm the results of our qRT-PCR analyses, we also performed ddPCR gene expression analyses on palatal shelf cDNA samples, following established protocols (Hindson et al., 2013). Briefly, oil-emulsified PCR reaction mixtures containing palatal shelf cDNA were amplified in 96-well plates on a Bio-Rad Tetrad 2 Peltier Thermal Cycler under the following conditions: $95^{\circ} \mathrm{C}$ for $10 \mathrm{~min}$ then 40 cycles of $95^{\circ} \mathrm{C}$ for $15 \mathrm{~s}$ and $60^{\circ} \mathrm{C}$ for $1 \mathrm{~min}\left(2.5^{\circ} \mathrm{C} / \mathrm{s}\right.$ ramp rate $)$ with a final $10 \mathrm{~min}$ hold at $98^{\circ} \mathrm{C}$. After amplification, the plates were transferred to a BioRad QX 100 Droplet Reader, which aspirated oil-emulsified PCR products from each well and counted numbers of FAM-positive and VIC-positive droplets, sampling at $100 \mathrm{kHz}$. Discrimination between droplets containing amplified target (positives) from those which did not (negatives) was achieved by applying a global fluorescence amplitude threshold. Gene transcript concentrations for each palatal RNA sample were calculated using dedicated ddPCR Poisson distribution computational modeling software (Bio-Rad ${ }^{\circledR}$ ). We employed the same Six2 and $\beta$-actin TaqMan assays for our ddPCR analyses as described in our qRT-PCR protocol.

\section{Western Blot Analysis}

Palatal shelves were dissected from wild-type or Hoxa2-/embryos and homogenized in RIPA Buffer $(150 \mathrm{mM} \mathrm{NaCl}$, $10 \mathrm{mM}$ Tris, $0.1 \%$-SDS, $1 \%$ Triton X-100, 1\% deoxycholate, $5 \mathrm{mM}$ EDTA) supplemented with a protease inhibitor cocktail (Sigma ${ }^{\circledR}$ ) as previously described (Brown and Nazarali, 2010). Sample aliquots containing equal total protein were loaded onto $10 \%$ polyacrylamide-SDS gels. Following electrophoresis, the proteins were transferred to Immunoblot PVDF membranes (Bio-Rad ${ }^{\circledR}$ ). The membranes were blocked overnight at $4^{\circ} \mathrm{C}$ in PBS containing 4\% skim milk, followed by incubation for $1 \mathrm{~h}$ at room temperature with rabbit polyclonal Six2 primary antibody (Proteintech ${ }^{\circledR}$; diluted 1:2,000 in PBS containing $4 \%$ skim milk). This was followed by four $15 \mathrm{~min}$ washes in PBST (PBS containing $0.08 \%$ Tween-20) and incubation for $1 \mathrm{~h}$ at room temperature with horseradish peroxidaseconjugated anti-rabbit secondary antibody (Bio-Rad ${ }^{\circledR}$; diluted 1:3,000 in PBS containing 4\% skim milk). After four $15 \mathrm{~min}$ washes in PBST, the membranes were incubated with Clarity ${ }^{\circledR}$ Western ECL substrate (Bio-Rad ${ }^{\circledR}$ ) and the signal detected using a SYNGENE ${ }^{\circledR}$ image analyzer. As a control for equal protein loading, the membranes were subsequently washed overnight at $4^{\circ} \mathrm{C}$ in PBS, followed by incubation with anti- $\beta$ tubulin (Developmental Studies Hybridoma Bank) at 1:2,000 dilution for $1 \mathrm{~h}$ at room temperature. Subsequently, membranes were washed with PBST, incubated with anti-mouse IgG horseradish peroxidase conjugate (Bio-Rad ${ }^{\circledR} ; 1: 2,000$ dilution), and processed for chemiluminescence protein detection as described above. After imaging, semi-quantitative densitometry was performed using AlphaView ${ }^{\circledR}$ software to generate an integrated density value for each Six 2 protein band, which was normalized to the $\beta$-tubulin density value from the same sample. Four separate Western blots, each having both wildtype and Hoxa2 ${ }^{-/-}$samples from E12.5, E13.5, E14.5, E15.5 palatal shelves, were performed. For each blot, the normalized Six2 expression values in the various samples (wild-type and Hoxa2 $2^{-/}$palates at E12.5, E13.5, E14.5, E15.5 stages) were compared to the value of the E12.5 wild-type sample on the same blot, which was arbitrarily assigned a relative expression level of 1. A total of four blots $(n=4)$ were analyzed using two-way ANOVA to compare Six 2 protein expression in wild-type and Hoxa $2^{-/-}$samples.

\section{Culture of Mouse Embryonic Palate Mesenchymal (MEPM) Cells}

Primary cultures of MEPM cells were established as previously described (Iwata et al., 2012; Iyyanar and Nazarali, 2017). Briefly, palatal shelves from E13.5 embryos were aseptically microdissected and placed in Hank's balanced salt solution. The palatal shelves were then incubated with $0.25 \%$ trypsin/EDTA in $\mathrm{Ca}^{+} / \mathrm{Mg}^{++}$-free $\mathrm{PBS}$ for $20 \mathrm{~min}$ at $37^{\circ} \mathrm{C}$, briefly triturated, 
and passed through a $70 \mu \mathrm{m}$ cell strainer (BD Falcon $\left.{ }^{\circledR}\right)$ to generate a dissociated mesenchymal cell suspension. Trypsin action was terminated by adding complete DMEM/F-12 medium (Dulbecco's Modified Eagle's Medium/Ham's medium F12 [1:1] supplemented with $10 \%$ fetal bovine serum, $1 \%$ antibiotic/antimycotic solution [Sigma $\left.{ }^{\circledR}\right]$, and L-glutamate) to the cell suspension. The cells were plated on poly-D-lysine coated plates and cultured at $37^{\circ} \mathrm{C}$ in $5 \% \mathrm{CO}_{2}$ incubator.

\section{siRNA Treatment and Cell Proliferation Analysis}

A pre-designed Six 2 siRNA (Invitrogen ${ }^{\circledR}$ Silencer Select assay s73795) and a negative control siRNA (Invitrogen ${ }^{\circledR}$ ) were utilized. MEPM cells $\left(5 \times 10^{3}\right)$ were plated in a 96 -well plate until they reached $60-80 \%$ confluency. Aliquots of $50 \mathrm{nM}$ siRNA were mixed with Lipofectamine 3000 (Invitrogen ${ }^{\circledR}$ ) according to the manufacturer's protocol. The siRNA-Lipofectamine complex $(10 \mu \mathrm{l})$ was added to each well of MEPM cells containing 100 $\mu \mathrm{l}$ of serum free medium. Following incubation at $37^{\circ} \mathrm{C}$ for $12 \mathrm{~h}$, the transfection medium was replaced with fresh medium. MEPM cells were analyzed for cellular DNA content after $48 \mathrm{~h}$ from the time of transfection using the CyQUANT NF cell proliferation assay kit (Life Technologies ${ }^{\circledR}$ ) following the manufacturer's protocol. Briefly, the transfected MEPM cells were incubated with $1 \mathrm{X}$ dye binding solution at $37^{\circ} \mathrm{C}$ for $45 \mathrm{~min}$ in the dark. Fluorescence was measured with a BioTek ${ }^{\circledR}$ microplate reader at $485 \mathrm{~nm}$ excitation and $530 \mathrm{~nm}$ emission wavelengths.

\section{Cell Density Determination}

Following IHC staining of histological sections, the number of Ki-67 positive mesenchymal cells in the palatal shelf were counted manually using Image $J$ software and this number was divided by the total cross-sectional area $\left(\mathrm{mm}^{2}\right)$ of the palatal mesenchyme. Additionally, the numbers of Ki-67 positive mesenchyme cells in the nasal vs. oral halves of the sectioned palatal shelves were counted and divided by their respective areas $\left(\mathrm{mm}^{2}\right) ; n=4$.

\section{Statistical Analyses}

All statistical analyses and graph construction were performed using GraphPad ${ }^{\circledR}$ Prism 5.0 software. The Western blot, gene expression, and cell count data were evaluated using two-way analysis of variance (ANOVA) followed by Bonferroni post-hoc tests.

\section{RESULTS}

\section{Six2 mRNA and Protein Are Expressed in the Developing Palate and Upregulated in Hoxa2 ${ }^{-/-}$Mice}

Our qRT-PCR analyses revealed that Six 2 mRNA is expressed in the developing palatal shelves of wild-type mouse embryos from E12.5 to E15.5, with highest expression at E12.5 and E13.5 (Figure 1A). The palatal shelves of $\mathrm{Hoxa}^{-/-}$null embryos showed a significant upregulation of Six 2 mRNA levels relative to wild-type palates at stages E12.5 to E14.5 (Figure 1A).
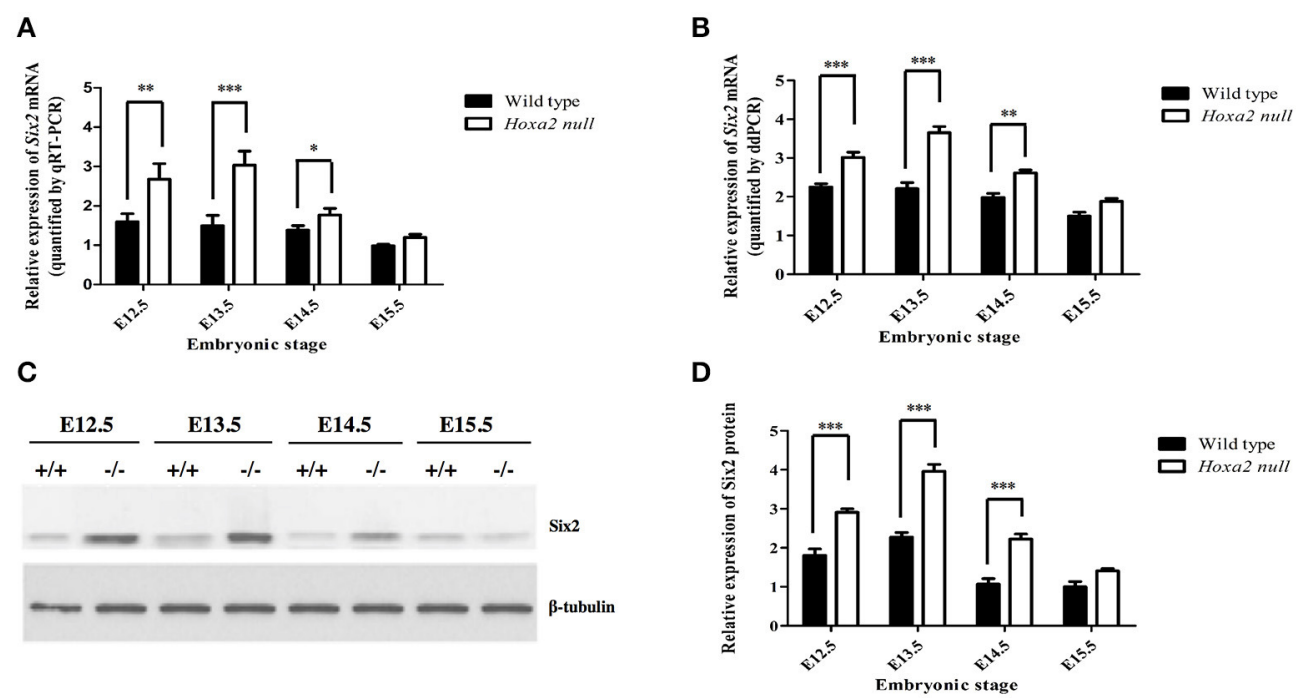

FIGURE 1 | Temporal changes in Six2 mRNA (A,B) and Six2 protein (C,D) levels in the palatal shelves of wild-type and Hoxa2-/- mouse embryos at developmenta stages E12.5-E15.5. (A) qRT-PCR analysis of relative levels of Six2 mRNA expression in the palatal shelves of wild-type and Hoxa2 ${ }^{-/-}$mouse embryos at developmental stages E12.5-E15.5. The Six2 mRNA expression values are normalized against expression levels of the $\beta$-actin reference gene $(n=5$ biological replicates). Note that Six2 mRNA levels were significantly higher in Hoxa2-/- palatal shelves compared to wild-type from stages E12.5 to E14.5. (B) Droplet digital PCR (ddPCR) quantification of relative Six2 mRNA levels in palatal shelves of wild-type and Hoxa2 ${ }^{-/}$embryos at stages E12.5-E15.5 ( $n=5$ biological replicates). Western blots (C) and corresponding densitometric measurements (D) of temporal changes in Six2 protein levels in wild-type and Hoxa2-/- palatal shelves during palatogenesis ( $n=4$ biological replicates). Note that Six2 protein is significantly upregulated in palatal shelves of Hoxa2 ${ }^{-/-}$embryos from E12.5 to E14.5. Two-way ANOVA followed by Bonferroni post-hoc test was performed for each analysis. Bars represent mean \pm SEM. ${ }^{*} p<0.05,{ }^{* *} p<0.01,{ }^{* \star *} p<0.001$. 
These trends were confirmed on independent biological samples using the ddPCR technique as an alternate method to quantify Six2 gene transcript levels (Figure 1B). Consistent with the Six 2 mRNA expression profiles, Western blot analysis revealed that Six2 protein is present in the developing palatal shelves from E12.5 to E15.5, with peak expression at E13.5 in wildtype embryos (Figures 1C,D). At stages E12.5 to E14.5, Six2 protein levels were significantly higher in Hoxa2 $2^{-/-}$palatal shelves compared to wild-type palatal shelves (Figure 1D). These results demonstrate that Six 2 is expressed intrinsically in the developing palate and is negatively regulated by Hoxa2 during palatogenesis.

\section{Six2 Protein Distribution in the Developing Secondary Palate Exhibits Temporal and Spatial Variations}

We next examined the spatial distribution of Six2 protein in the developing SP. IHC analyses of mid-coronal sections of heads from wild-type mouse embryos revealed abundant Six2 protein expression in the mesenchyme of the palatal shelves from stages E12.5 to E15.5 (Figures 2A-D). The intensity of Six 2 immunostaining in the palatal shelf mesenchyme of wildtype embryos appeared higher at earlier stages of palatogenesis (E12.5-E13.5) (Figures 2A,B) compared to later stages (E14.5E15.5) (Figures 2C,D). At stages E12.5 and E13.5, prior to palatal shelf elevation, Six2 protein was observed throughout the palatal mesenchyme in both the prospective "nasal half" of the palatal shelf (located nearest the tongue at these pre-elevation stages) as well as in the "oral half" of the palatal shelf (located furthest from the tongue) (Figures 2A,B). However, by E14.5 to E15.5, after the wild-type palatal shelves have reoriented to a horizontal position above the tongue, there was a conspicuous loss of Six 2 immunostaining within a layer of palatal mesenchyme located in the nasal half of the palatal shelf, immediately subjacent to the surface palatal epithelium (Figures 2C,D). In contrast, Six2 protein expression persisted throughout the palatal mesenchyme in the oral half of the palatal shelf in wild type embryos (Figures 2C,D).

The palatal shelves of Hoxa2 null embryos, unlike those of wild-type embryos, fail to elevate and instead remain oriented vertically downward on either side of the developing tongue (Figures 2E-H). Within these Hoxa2 $2^{-/-}$palatal shelves, Six2 protein expression persisted through stage E15.5 in palatal mesenchyme cells of both the nasal half of the palatal shelf (positioned nearest the tongue) as well as the oral half of the palatal shelf (located furthest from the tongue) (Figures 2E-H). Therefore, in comparison to wild-type embryos, the loss of Hoxa2 function expands the spatial domain of Six2 expression within the palatal mesenchyme at stages E14.5-E15.5 (compare Figures 2A-D to Figures 2E-H).

The outer epithelial cell layer that coats the nasal and oral surfaces of the palatal shelf displayed a strikingly different pattern of Six 2 protein distribution. In wild-type palatal shelves, Six2 immunostaining was prominent in the surface epithelium located on the nasal side of the palatal shelf at both pre-elevation and post-elevation stages (Figures 2A-D; Figures 3A,B). Conversely, Six2 protein was undetectable in the surface epithelium located
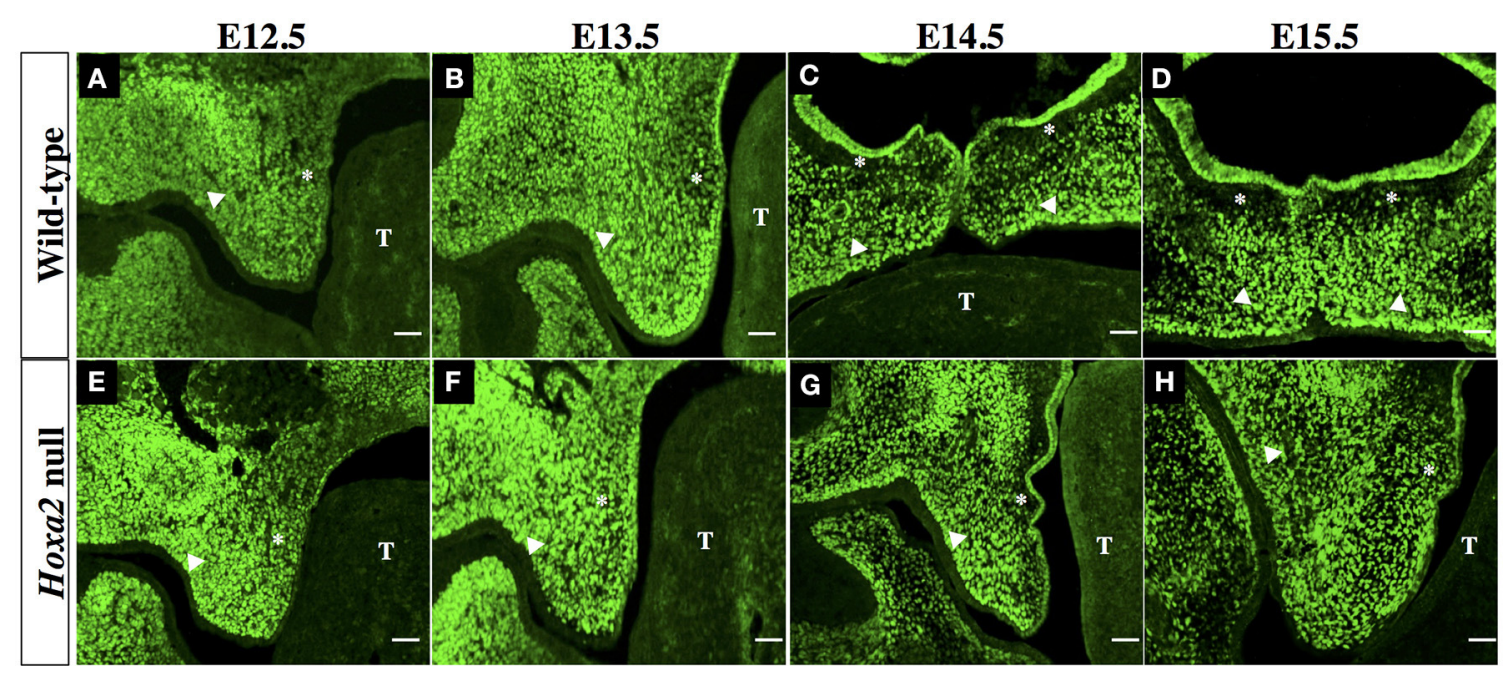

FIGURE 2 | Immunohistochemical (IHC) analysis of Six2 localization in the palatal shelves of wild-type (A-D) and Hoxa2 null embryos (E-H) at developmental stages E12.5 (A,E), E13.5 (B,F), E14.5 (C,G), and E15.5 (D,H). Photomicrographs are mid-coronal sections, and are representative of a minimum of 5 biological replicates per stage. In each photograph, the asterisk indicates the nasal half of the palatal shelf and the arrow head indicates the oral half of the palatal shelf. T, identifies the developing tongue. Six2 immunostaining in the mesenchyme of wild-type palatal shelves appeared most intense at stages E12.5 (A) and E13.5 (B), and was uniformly distributed throughout the palatal shelf at these early stages. However, by stages E14.5 (C) to E15.5 (D) there was a pronounced decline in Six2 expression by a layer of mesenchyme cells in the nasal half of the palatal shelf lying immediately beneath the palatal epithelium. In Hoxa2 ${ }^{-1-}$ embryos (E-H), Six2 immunostaining persisted throughout the palatal mesenchyme within the nasal half as well as the oral half of the palatal shelf at all stages from E12.5-15.5 (E-H). Note that the palatal shelves of Hoxa2 null embryos fail to elevate and remain oriented vertically alongside the tongue (G,H). Scale bar, $50 \mu \mathrm{m}$. 

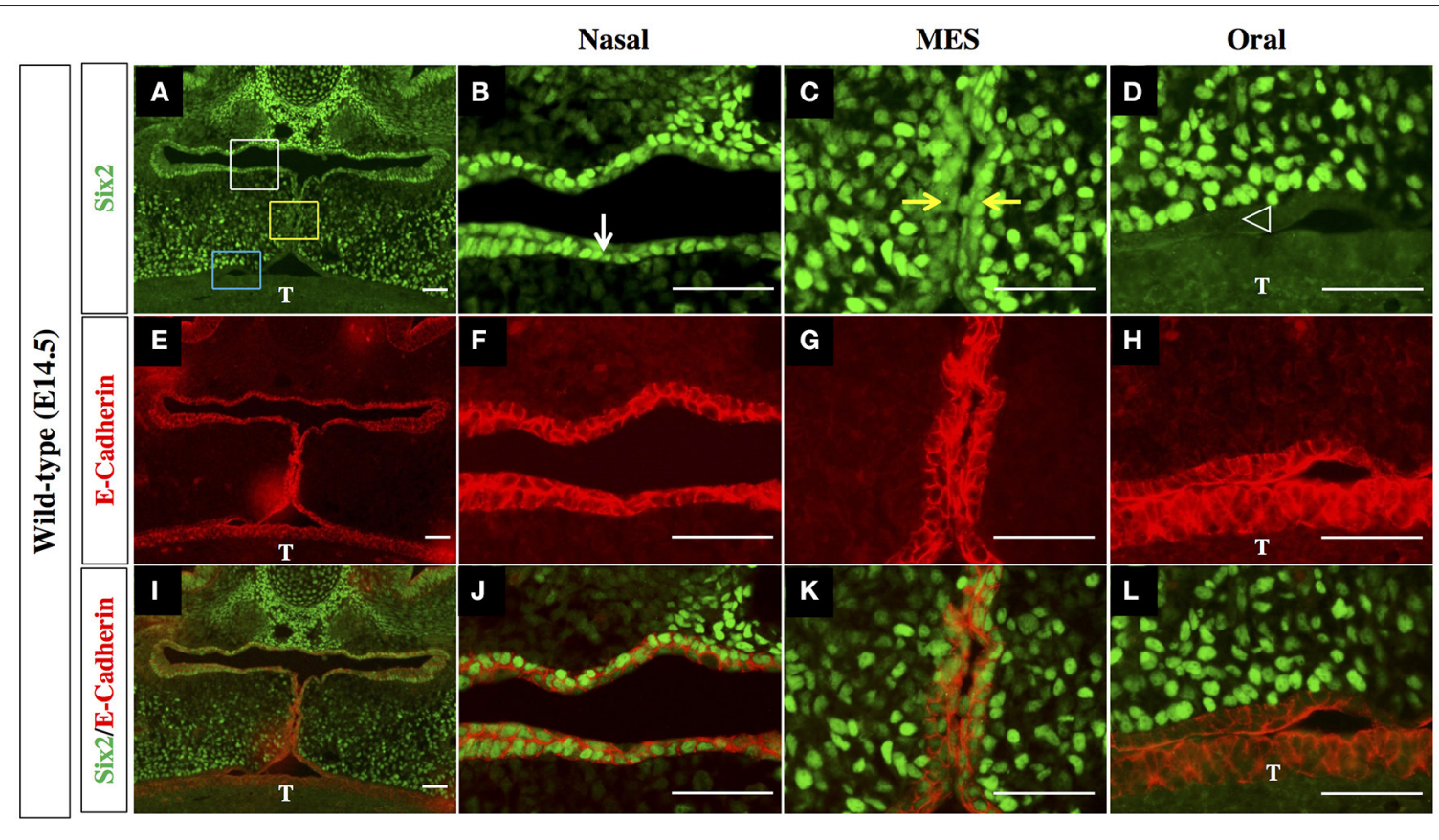

FIGURE 3 | Six2 protein is differentially expressed by epithelium on the nasal side vs. the oral side of the palatal shelf in wild-type mice. IHC staining of mid-coronal sections of wild-type palatal shelves at E14.5 for Six2 (A-D) and E-Cadherin (E-H). Panels I-L are the Six2 immunofluorescence images overlaid with the E-Cadherin immunofluorescence images to identify cells co-expressing the two proteins. Six2 protein expression is prominent in epithelial cells located on nasal side of the palata shelf (marked by the white rectangle in panel (A), and by the white arrow in panel (B), where it is co-expressed with the epithelial marker E-cadherin (E,F,I,J). Six2 is also expressed in epithelial cells of the MES (marked by yellow rectangle in panel A, and by yellow arrows in panel (C), which is the point of contact between the apical tips of the two elevated palatal shelves. In contrast, Six2 protein is absent from the epithelium on the oral side of the palatal shelf [marked by the blue rectangle in panel (A) and by position of the arrowhead in panel (D)], which expresses E-cadherin alone (E,H,I,L). MES, midline epithelial seam; T, tongue. Scale bars, $50 \mu \mathrm{m}$. The $\mathrm{IHC}$ staining images shown are representative of palatal sections from a minimum of 5 embryos.

on the oral side of the palatal shelf (Figures 2A-D, 3A,D). The pattern of Six 2 expression within the palatal epithelium was largely unaffected by loss of Hoxa2 function. In Hoxa2 $2^{-/-}$ embryos, like wild-type embryos, Six 2 expression was prominent in epithelial cells located on the nasal side of the palatal shelf (facing the tongue), with little or no Six2 protein detectable in the epithelium covering the oral side of the palatal shelf (located furthest from the tongue) (Figures 2E-H, 4A,B,D). These findings were confirmed by co-staining palatal sections from wild-type (Figure 3) and Hoxa2 $2^{-/-}$embryos (Figure 4) with an antibody for E-cadherin, a characteristic epithelial marker (Figures 3E-L, 4E-L). Examination of the palatal sections at high magnification revealed that the surface epithelium on the nasal side of the palatal shelf co-expressed both Six 2 and E-cadherin proteins in wild-type embryos (Figures $\mathbf{3 B}, \mathbf{F}, \mathbf{J}$ ) as well as in Hoxa2 $2^{-/-}$mutants (Figures 4B,F,J). By contrast, epithelial cells on the oral side of the palatal shelf were positive for E-cadherin alone in both wild-type (Figures 3D,H,L) and Hoxa2 ${ }^{-/-}$embryos (Figures 4D,H,L).

Interestingly, in the palatal shelves of E14.5 wild-type embryos, we also observed prominent expression of Six2 together with E-cadherin within cells of the MES, the point of contact/adhesion between the apical tips of the two horizontally elevated palatal shelves (Figures 3C,G,K). However, Six2 immunostaining was only faintly visible in medial edge epithelium (MEE) cells located at the apical tips of the Hoxa2 $2^{-/-}$ palatal shelves, which fail to elevate and make midline contact (Figures 4C,G,K).

\section{Expression of the Ki-67 Cell Proliferation Marker Is Enhanced in the Hoxa2-/- Palatal Shelves}

To explore the relationships between Six2, Hoxa2 and cell proliferation during SP development, we performed double immunofluorescence staining on histological sections from the anterior, middle, and posterior regions of E13.5 wild-type and Hoxa2 null palatal shelves using Six 2 antibody in combination with an antibody for Ki-67, a nuclear protein expressed exclusively in proliferating cells (Figure 5).

We observed that the mesenchyme of both wild-type and Hoxa2 $2^{-/}$palatal shelves contained large numbers of proliferating, Ki-67 positive cells (Figures 5C,D). Cell counts performed on the immunostained sections revealed that the number of Ki-67 positive palatal mesenchyme cells per unit area was significantly higher in Hoxa2 $2^{-/-}$palatal shelves compared to wild-type in both the anterior and posterior regions of the palate (Figure 6A). This trend was also observed in the middle region of the palate, although the difference there was not statistically significant. Interestingly, in all three regions along the A-P axis 


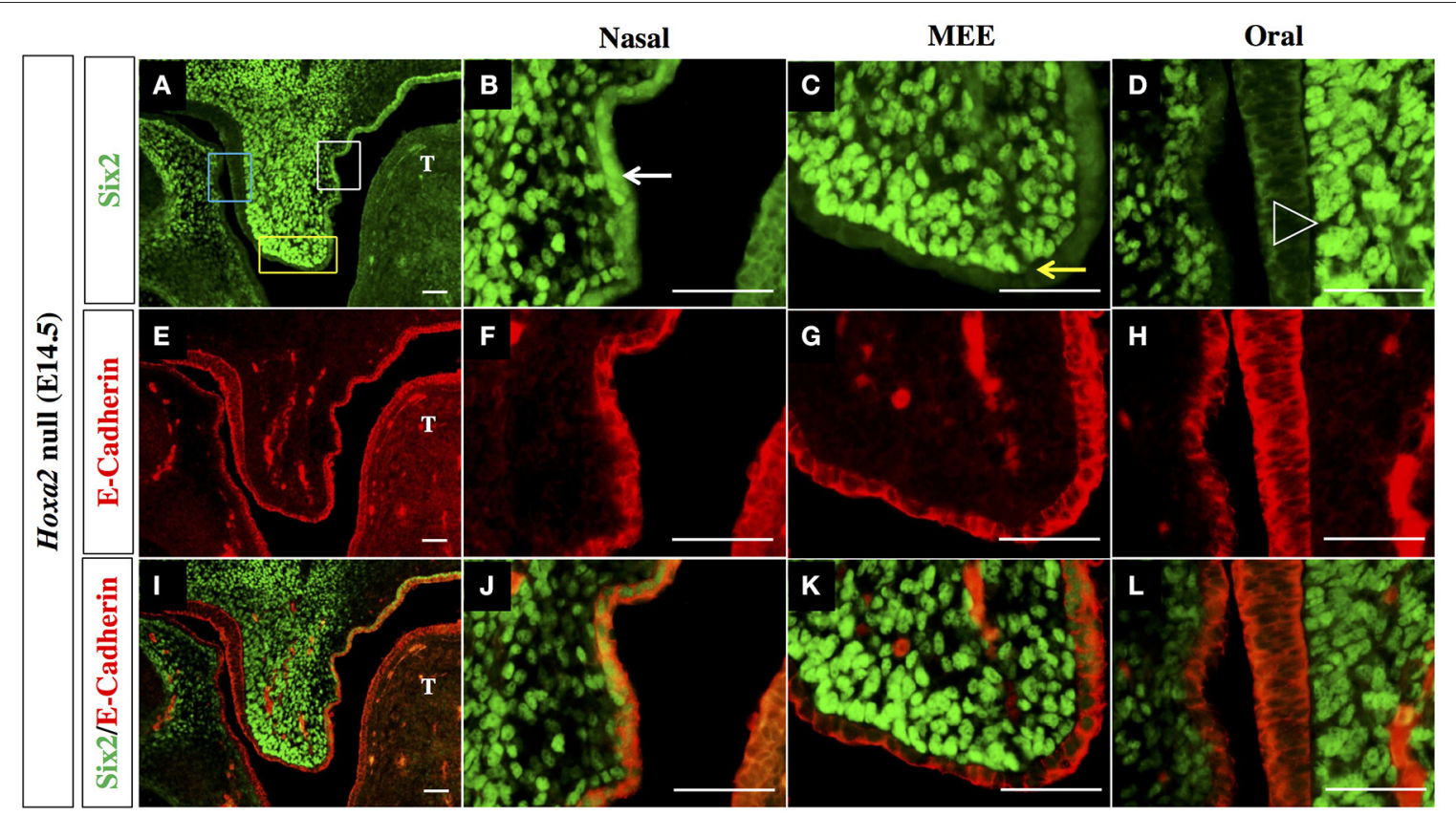

FIGURE 4 | Six2 protein is exclusively expressed in epithelium on the nasal side of the palatal shelf in Hoxa2 ${ }^{-/-}$mice. IHC staining of mid-coronal sections of Hoxa2 null palatal shelves at E14.5 for Six2 (A-D), E-Cadherin (E-H), and overlays of the Six2 and E-Cadherin immunofluorescence images (I-L). Expression of Six2 protein within the palatal epithelium is restricted to epithelial cells located on the nasal side of the palatal shelf (marked by white rectangle in panel (A), and by white arrow in the higher magnification image (B). Six2 is absent from epithelial cells located on the oral side of the palatal shelf (marked by blue rectangle in $\mathbf{A}$, and by position of arrowhead in higher magnification image D). Within Hoxa2 ${ }^{-/-}$embryos, Six2 is also absent from cells of the medial edge epithelium (MEE) which is located at the apical tip of the palatal shelf (marked by yellow rectangle in (A), and by yellow arrow in higher magnification image (C). Because palatal shelves of Hoxa2 $-1-$ fail to elevate and make contact, they do not form an MES. The entire surface epithelium of Hoxa2 ${ }^{-/-}$palatal shelves (on both its nasal and oral sides, as well as within the MEE) expresses E-cadherin (E-H, I-L). MEE, medial edge epithelium; T, tongue. Scale bars, $50 \mu \mathrm{m}$. The IHC staining images shown are representative of palatal sections from a minimum of 5 embryos.

of the palate (anterior, middle, and posterior), the density of proliferating Ki-67 positive mesenchyme cells was significantly higher in the nasal half of the palatal shelf compared to its oral half (Figure 6B). This was the case for both wild-type as well as Hoxa2 null embryos (Figure 6B).

Many Six2-expressing palatal mesenchyme cells in both wildtype and Hoxa2 null embryos were actively proliferating, as evidenced by Ki-67 co-expression (Figures 5E, F). Cell counts revealed that the numbers of these Six $2 / \mathrm{Ki}-67$ double-positive palatal mesenchyme cells per unit area were significantly higher in Hoxa2 $2^{-1}$ mice compared to wild-type in all three regions along the A-P axis of the palate (anterior, middle, and posterior) (Figure 6C).

\section{Six2 Knockdown Reduces Cell Proliferation and Cyclin D1 Expression in MEPM Palatal Mesenchyme Cell Cultures}

We next investigated whether Six2 is a positive regulator of cell proliferation in the palatal mesenchyme and whether upregulation of Six2 is responsible for the increased cell proliferation in $\mathrm{Hoxa}^{-/-}$palatal mesenchyme. Primary cultures of MEPM cells were transfected with siRNA targeting Six 2 mRNA to determine the effects of Six 2 knockdown on proliferation of palatal mesenchyme cells in vitro. As shown in Figure 7A, treatment with Six2 siRNA resulted in $\sim 90 \%$ reduction in Six2 mRNA expression in MEPM cultures when compared to cultures administered either siRNA delivery vehicle alone (mock treatment) or a non-targeting negative control siRNA. Importantly, siRNA-mediated Six2 knockdown decreased cell proliferation in both wild-type and Hoxa2 $2^{-/-}$MEPM cultures (Figure 7B) and also reduced mRNA levels of Cyclin D1, a cell cycle regulator (Figure 7C). In the Hoxa2 $2^{-/-}$MEPM cultures, Six2 knockdown restored both cell proliferation and Cyclin D1 expression down to levels approximating those of wildtype control MEPM cultures treated with either siRNA delivery vehicle alone or the negative control siRNA (Figures 7B,C).

\section{DISCUSSION}

Previous studies have established that the Six2 gene is expressed within multiple regions and tissues of vertebrate embryos, including the developing head, pharyngeal arches, and kidneys (Oliver et al., 1995; Kutejova et al., 2005; Fogelgren et al., 2008). Furthermore, Six2 mutations are linked to embryonic craniofacial and renal malformations (Singh et al., 1998; McBratney et al., 2003; Self et al., 2006; Fogelgren et al., 2008, 2009), which appear to result in part from reduced cell proliferation during organogenesis (Self et al., 


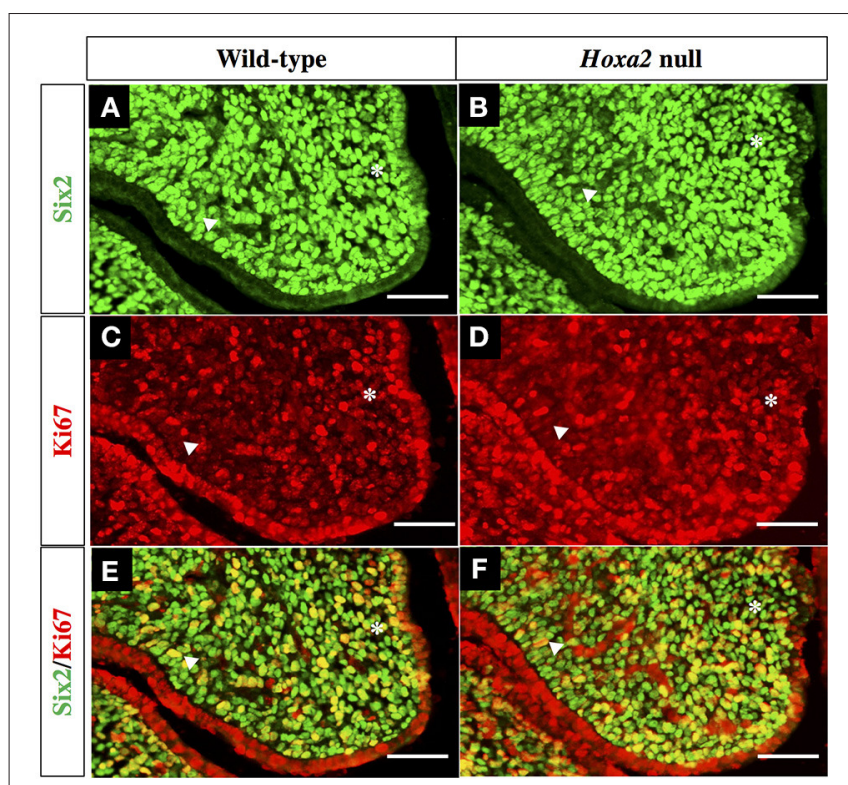

FIGURE 5 | Double IHC staining of wild-type and Hoxa2 ${ }^{-/-}$palatal shelves with antibodies for Six2 as well as Ki-67, a marker of proliferating cells. Representative coronal sections from the middle region of E13.5 wild-type palatal shelves (A,C,E) and Hoxa2 ${ }^{-/-}$palatal shelves (B,D,F). Green fluorescence in panels $(\mathbf{A}, \mathbf{B})$ identifies Six2 expressing cells, whereas red fluorescence in panels (C,D) identifies all cells expressing proliferation marker Ki-67. Panels (E,F) are overlays of the Six2 (A,B) and Ki-67 (C,D) immunofluorescence images to identify cells that co-expressed Six2 together with Ki-67. Both wild-type (E) and Hoxa2 ${ }^{-/-}$(F) palatal shelves contained numerous Six2/Ki-67 double-positive mesenchyme cells, which appear yellow in these image overlays. Six2/Ki-67 double-positive cells appear higher in the Hoxa2 ${ }^{-/-}$palate. Asterisk indicates the nasal half of the palatal shelf and the arrowhead indicates the oral half of the palatal shelf. Scale bars, $50 \mu \mathrm{m}$. The $\mathrm{IHC}$ staining images shown are representative of palatal sections from a minimum of four wild-type and four Hoxa2 null embryos.

2006; He et al., 2010). Our present study demonstrates, for the first time, that Six2 transcripts and Six2 protein are expressed endogenously within the palatal shelves of wildtype mouse embryos throughout the period of normal SP formation. Moreover, we found that Six2 expression within the palatal primordia is both temporally modulated and spatially heterogeneous.

Our gene expression and Western blot data indicate that Six2 mRNA and protein levels are quantitatively highest during the early stages of SP formation (E12.5-13.5), when the palatal shelves emerge as paired outgrowths of the two maxillary prominences and grow vertically downwards on either side of the developing tongue. Six 2 mRNA and protein expression persist, albeit at quantitatively lower levels, within the palatal processes during the subsequent phases of palatal shelf elevation, contact, and fusion (at E14.5-E15.5) which culminate in the separation of the oral and nasal cavities. The lateral palatine processes undergo progressive enlargement during early phases of palatogenesis, suggesting the possibility that the Six2 transcription factor may assist in promoting palatal shelf tissue growth. Supporting this possibility, we have demonstrated that siRNA-mediated knockdown of Six 2 mRNA expression in cultures of palatal shelf mesenchyme cells resulted in reduced mesenchymal cell proliferation as well as reduced mRNA levels of the cell cycle regulator, Cyclin D1.

In addition to the temporal variation in Six2 expression levels during SP development, our IHC analyses revealed intriguing heterogeneity in its spatial distribution within the mesenchyme and epithelium of the growing palatal shelves. Within the palatal mesenchyme of wild-type embryos, Six2 protein was expressed uniformly throughout mesenchymal cells located in the prospective oral half of the palate, at stages both prior to and following palatal shelf elevation. By contrast, palatal shelf elevation in wild-type embryos was accompanied by a marked loss of Six 2 expression by a band of palatal mesenchyme cells located in the nasal half of the palatal shelf. Interestingly, a somewhat converse pattern of Six 2 distribution was observed in the surface epithelium of the palatal shelves, such that Six2 expression was prominent within epithelial cells located on the nasal side of each palatal shelf, whereas little or no Six 2 protein was detectable within epithelial cells on the oral side of the palatal shelves. Several other genes have been previously shown to exhibit differential expression along the oro-nasal $(\mathrm{O}-\mathrm{N})$ axis of the developing SP. Like Six2, the Fgf10 (Rice et al., 2004), Foxf1 (Lan and Jiang, 2009; Xu et al., 2016), Gli1 (Han et al., 2009; Lan and Jiang, 2009), Osr2 (Lan and Jiang, 2009), and Ptch1 (Lan and Jiang, 2009) genes are all predominantly expressed in the oral half of the palatal mesenchyme (reviewed in Bush and Jiang, 2012). Conversely, Pax 9 exhibits higher expression in mesenchyme in the nasal half of palatal shelf (Lan et al., 2004; Zhou et al., 2013). It remains to be explored whether the localized expression of Six2 along the O-N axis in the palatal mesenchyme or the palatal epithelium either regulates or is regulated by, the domains of expression of any of these other genes. Alternatively, the loss of Six 2 expression by a population of mesenchymal cells in the nasal half of the palatal shelf might be a consequence of the onset of osteogenic differentiation in this location, since bone formation during SP development is confined to the nasal half of the palatal shelves (Han et al., 2009; Baek et al., 2011). A number of transcription factors and signaling molecules also demonstrate gradations in their expression levels along the A-P (anteriorposterior) axis of the developing SP including $M s x 1, B m p 4$, Bmp2, Shh, Spry2, Fgf10, Fgf7, Shox2, Meox2, Tbx22, and Barx1 (reviewed in Bush and Jiang, 2012; Smith et al., 2013). However, our study revealed no significant quantitative differences in Six2 expression levels between anterior, middle and posterior regions of the palate.

Our study also examined the relationship between Hoxa2 function within the developing palatal shelves and the regulation of Six2 expression therein. Our gene expression and Western blot analyses revealed that Six 2 mRNA and Six2 protein levels are significantly elevated in palatal shelves of Hoxa2 ${ }^{-/-}$mouse mutants, and our IHC data demonstrate that the domain of Six2 expression in Hoxa2-null palatal shelf mesenchyme is ectopically expanded to include the entire nasal half of the palatal shelf in addition to the oral half. These findings suggest that Hoxa2 acts as a negative regulator of Six2 expression within palatal shelf mesenchyme. Consistent with our observations, earlier studies by Kutejova et al. $(2005,2008)$ showed that the Six2 gene is an 

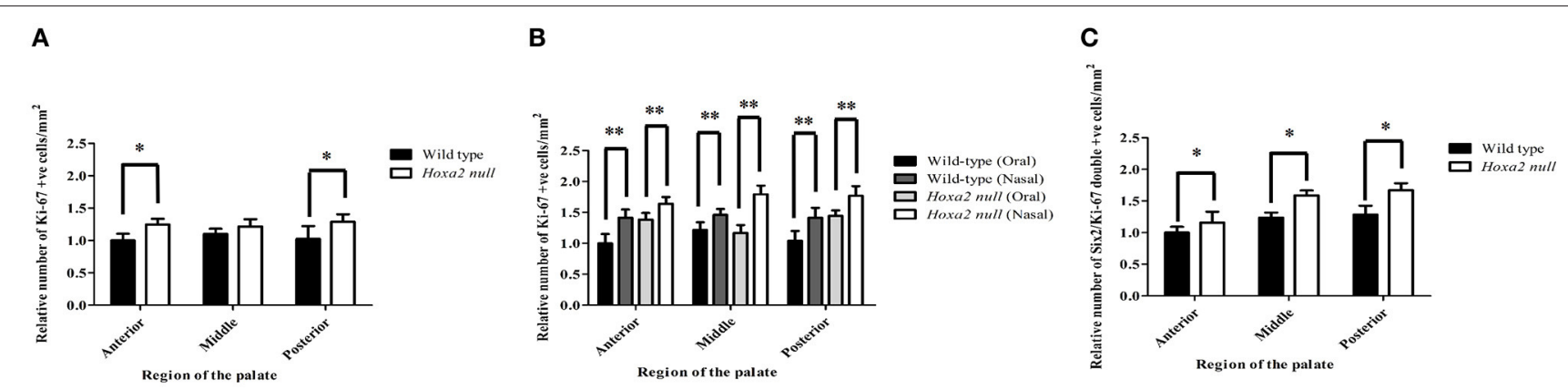

FIGURE 6 | The densities of proliferating, Ki-67 positive and Six2/Ki-67 double-positive mesenchyme cells are elevated in Hoxa2-/- palatal shelves compared to wild-type. (A) Relative numbers of Ki-67 positive palatal mesenchyme cells per $\mathrm{mm}^{2}$ in coronal sections taken from anterior, middle and posterior regions of E13.5 wild-type and Hoxa2 ${ }^{-/}$palatal shelves. In the anterior and posterior regions, the density of proliferating palatal mesenchyme cells was significantly higher in Hoxa2 ${ }^{-/-}$palatal shelves compared to wild-type. (B) In both wild-type and Hoxa2 ${ }^{-/-}$palatal shelves, the density of proliferating palatal mesenchyme cells was consistently higher in the nasal half vs. the oral half of the palatal shelf. (C) Relative numbers of Six2-positive mesenchyme cells that co-expressed Ki-67 (i.e., were actively proliferating) in the anterior, middle and posterior regions of Hoxa2 ${ }^{-/-}$palatal shelves compared to wild-type. Bar graphs represent mean \pm SEM; $n=4$ biological replicates. ${ }^{*} p<0.05,{ }^{* *} p<0.01$.

A

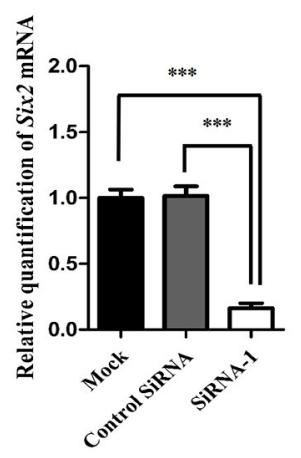

B

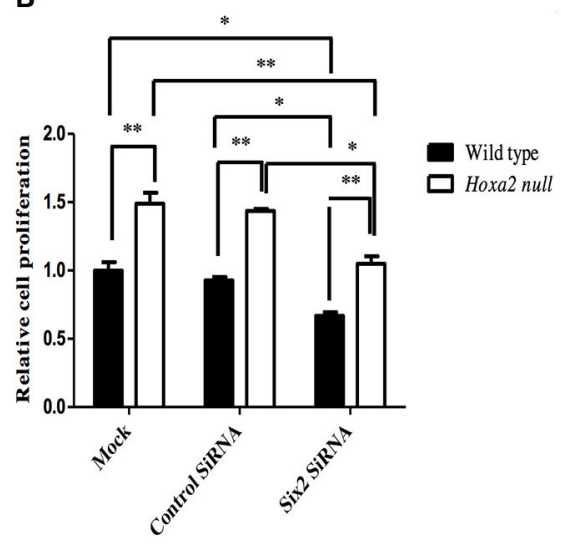

C

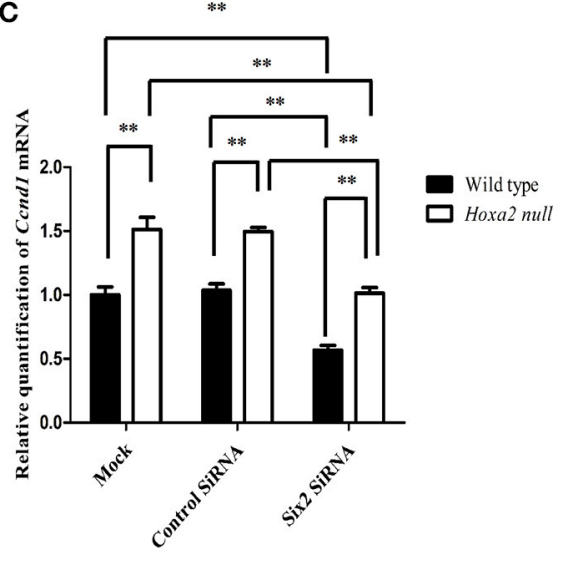

FIGURE 7 | Six2 knockdown in wild-type and Hoxa2 $-/-$ mouse embryonic palate mesenchyme (MEPM) cultures reduces cell proliferation and Cyclin D1 expression. (A) Treatment of MEPM cultures with Six2 siRNA decreased Six2 mRNA expression by $90 \%$ compared to cultures administered either a negative control siRNA or siRNA delivery-vehicle alone (mock treatment). (B) Six2 siRNA treatment significantly decreased cell proliferation in both wild-type MEPM and Hoxa2 ${ }^{-/-}$MEPM cultures and also reduced expression of Cyclin D1 mRNA (C). Note that levels of cell proliferation (B) and Cyclin D1 expression (C) in Hoxa2-/- MEPM cultures were consistently higher than those of parallel wild-type cultures in all three treatment groups. Also, Six 2 knockdown restored cell proliferation and Cyclin D1 expression in Hoxa2 ${ }^{-/-}$MEPM cultures to levels approximating those of control wild-type MEPM cultures. Bars represent mean \pm SEM; $n=4$ biological replicates. ${ }^{\star} p<0.05,{ }^{* \star} p$ $<0.01,{ }^{\star \star *} p<0.001$

immediate downstream target of transcription factor Hoxa2 in the second pharyngeal arch which, through negative regulation, confines Six2 expression to the more anterior first pharyngeal arch. Previous investigations in our own laboratory have shown that the Hoxa2 gene is expressed endogenously in the epithelium and mesenchyme of the developing palatal shelves (Nazarali et al., 2000; Smith et al., 2009). However, unlike Six2, we have observed no conspicuous difference in Hoxa2 expression levels between the oral and nasal halves of the palate. Therefore, other genes in addition to Hoxa 2 must regulate Six 2 expression domains within the palatal mesenchyme of wild-type embryos to account for the greater Six 2 protein abundance in the oral half of the palatal shelf vs. the nasal half. Moreover, within the outer epithelium layer of the palate, the spatial expression pattern of Six 2 must be independent of Hoxa2 function, since Six 2 protein remains confined to epithelial cells on the nasal side of the palatal shelf in Hoxa2 $2^{-/-}$mutants, as it is in wild-type embryos.

The palatal shelves originate from outgrowths of the maxillary prominence derivatives of pharyngeal arch 1 . However, somewhat paradoxically, Hoxa2 expression is normally absent from tissue of the first pharyngeal arch itself, and the loss of Hoxa2 function in $\mathrm{Hoxa2}^{-1-}$ mutant mice leads to ectopic formation of arch 1 skeletal structures in place of arch 2 elements (Gendron-Maguire et al., 1993; Rijli et al., 1993). Studies from several labs have shown that Hoxa2 null mice develop cleft palate defects in vivo (Gendron-Maguire et al., 1993; Rijli et al., 1993; Barrow and Capecchi, 1999). We have previously demonstrated that Hoxa2 knockdown in whole 
palatal organ culture explants resulted in failure of the palatal shelves to fuse ex vivo (Smith et al., 2009). We have now extended those findings by showing that the cleft palate defects in Hoxa2 $2^{-/}$palatal shelves are accompanied by elevated levels and spatially expanded expression of Six 2 protein, as well as increased proliferation of the palatal mesenchyme cells. This suggests the possibility that Six2 expression within the normally developing SP may positively regulate palatal mesenchyme cell proliferation and, furthermore, that the increased mesenchymal cell proliferation observed in Hoxa2 null palatal mesenchyme may result from increased expression of endogenous Six2. This is supported by our observation that, in vivo, the numbers of palatal mesenchyme cells that co-express Six2 together with the cell proliferation marker Ki-67 are higher in Hoxa2 $2^{-/-}$ palatal shelves than wild-type palatal shelves. Moreover, we demonstrated that treatment of wild-type palate mesenchymal cell cultures with Six2 siRNA to knockdown Six2 expression led to significant reductions in both cell proliferation and Cyclin D1 mRNA levels. Indeed, whereas Hoxa2 ${ }^{-/-}$MEPM cultures otherwise displayed enhanced cell proliferation, Six2 knockdown in the Hoxa2 null cultures restored mesenchymal proliferation to wild-type levels.

From our findings, it appears likely that increased Six2 expression leading to a rise in the level of palatal mesenchyme proliferation is responsible, at least in part, for the generation of cleft palate defects in Hoxa2 $2^{-/-}$embryos. This is consistent with studies from other laboratories that have implicated increased mesenchymal proliferation as contributing to cleft palate formation in Wnt5a-/- (He et al., 2008) and Sprouty $2^{-/-}$ mice (Welsh et al., 2007; Matsumura et al., 2011), as well as in embryos expressing $F g f 8$ ectopically in palatal mesenchyme (Wu et al., 2015). Apparently, rates of mesenchymal cell proliferation must be tightly regulated for normal growth, morphogenesis and elevation of the palatal shelves, with either increased or decreased proliferation of palatal mesenchyme potentially leading to cleft palate defects (reviewed in Smith et al., 2013).

In summary, our study is the first to specifically investigate the expression and cell proliferation function of Six2 in the developing SP. We have demonstrated that Six 2 mRNA and protein exhibit dynamic temporal and spatial expression profiles within the mouse SP from embryonic stages E12.5 through to E15.5. We observed that Six 2 protein is present within both the mesenchyme and epithelium of the developing SP; however, its

\section{REFERENCES}

Baek, J. A., Lan, Y., Liu, H., Maltby, K. M., Mishina, Y., and Jiang, R. (2011). Bmprla signaling plays critical roles in palatal shelf growth and palatal bone formation. Dev. Biol. 350, 520-531. doi: 10.1016/j.ydbio.2010.12.028

Barrow, J. R., and Capecchi, M. R. (1999). Compensatory defects associated with mutations in Hoxal restore normal palatogenesis to Hoxa2 mutants. Development 126, 5011-5026.

Brown, G. D., and Nazarali, A. J. (2010). Matrix metalloproteinase-25 has a functional role in mouse secondary palate development and is a downstream target of TGF- $\beta 3$. BMC Dev. Biol. 10:93. doi: 10.1186/1471-213X-10-93

Bush, J. O., and Jiang, R. (2012). Palatogenesis: morphogenetic and molecular mechanisms of secondary palate development. Development 139, 231-243. doi: $10.1242 /$ dev.067082 spatial distribution within these two cell populations displays an intriguing pattern of complementarity along the O-N axis of the palatal shelf. Additionally, we demonstrated that Six2 functions downstream of Hoxa2, which negatively regulates Six2 expression. Finally, we provide new evidence supporting a role for Six 2 as a positive regulator of mesenchymal cell proliferation in the developing SP.

\section{AUTHOR CONTRIBUTIONS}

AN conceived and coordinated the study, with assistance from WK. DO together with PI designed and performed experiments, analyzed the data, and prepared initial manuscript drafts. AN and WK extensively revised subsequent versions of the manuscript contents and interpretations of results. TS performed pilot experiments that laid the foundation for this investigation. SL was involved in the initial study design and critically reviewed the manuscript. SJ assisted with experimental design and data analysis. All authors approved the final manuscript version for submission.

\section{FUNDING}

This work was supported by Discovery Grant 171317-2012 to AN from the Natural Sciences and Engineering Research Council of Canada (NSERC) and, in part, by NSERC Discovery Grant 121407-2012 to WK.

\section{ACKNOWLEDGMENTS}

DO was supported in part by graduate funding from the University of Saskatchewan, College of Pharmacy and Nutrition. PI was the recipient of an Apotex Graduate Scholarship Award from the College of Pharmacy and Nutrition, University of Saskatchewan, as well as a Graduate Research Fellowship and a Saskatchewan Innovation and Opportunity Scholarship from the College of Graduate and Postdoctoral Studies, University of Saskatchewan. TS was recipient of an NSERC Postgraduate Scholarship. The authors thank L. Sobschishin and K. Schroeder for their technical expertise. This manuscript is dedicated to the memory of our esteemed colleague and mentor, Dr. Adil J. Nazarali, who was the lead investigator on this study.

Dixon, M. J., Marazita, M. L., Beaty, T. H., and Murray, J. C. (2011). Cleft lip and palate: understanding genetic and environmental influences. Nat. Rev. Genet. 12, 167-178. doi: 10.1038/ nrg2933

Ferguson, M. W. (1988). Palate development. Development 103(Suppl.), 41-60.

Fogelgren, B., Kuroyama, M. C., McBratney-Owen, B., Spence, A. A., Malahn, L. E., Anawati, M. K., et al. (2008). Misexpression of Six2 is associated with heritable frontonasal dysplasia and renal hypoplasia in $3 \mathrm{H} 1 \mathrm{Br}$ mice. Dev. Dyn. 237, 1767-1779. doi: 10.1002/dvdy2.1587

Fogelgren, B., Yang, S., Sharp, I. C., Huckstep, O. J., Ma, W., Somponpun, S. J., et al. (2009). Deficiency in Six2 during prenatal development is associated with reduced nephron number, chronic renal failure, and hypertension in Br/t adult mice. Am. J. Physiol. Renal Physiol. 296, F1166-F1178. doi: 10.1152/ajprenal.90550.2008 
Gendron-Maguire, M., Mallo, M., Zhang, M., and Gridley, T. (1993). Hoxa-2 mutant mice exhibit homeotic transformation of skeletal elements derived from cranial neural crest. Cell 75, 1317-1331. doi: 10.1016/0092-8674(93)90619-2

Gritli-Linde, A. (2007). Molecular control of secondary palate development. Dev. Biol. 301, 309-326. doi: 10.1016/j.ydbio.2006.07.042

Gu, Y., Zhao, Y., Zhou, Y., Xie, Y., Ju, P., Long, Y., et al. (2016). Zeb1 Is a potential regulator of six2 in the proliferation, Apoptosis and migration of metanephric mesenchyme Cells. Int. J. Mol. Sci. 17:1283. doi: 10.3390/ijms17081283

Han, J., Mayo, J., Xu, X., Li, J., Bringas, P., Maas, R. L., et al. (2009). Indirect modulation of Shh signaling by Dlx 5 affects the oral-nasal patterning of palate and rescues cleft palate in Msx1-null mice. Development 136, 4225-4233. doi: 10.1242/dev.036723

He, F., Xiong, W., Yu, X., Espinoza-Lewis, R., Liu, C., Gu, S., et al. (2008). Wnt5a regulates directional cell migration and cell proliferation via Ror2-mediated noncanonical pathway in mammalian palate development. Development 135, 3871-3879. doi: 10.1242/dev.025767

He, G., Tavella, S., Hanley, K. P., Self, M., Oliver, G., Grifone, R., et al. (2010). Inactivation of Six 2 in mouse identifies a novel genetic mechanism controlling development and growth of the cranial base. Dev. Biol. 344, 720-730. doi: 10.1016/j.ydbio.2010.05.509

Hindson, C. M., Chevillet, J. R., Briggs, H., A, Gallichotte, E. N., Ruf, I. K., Hindson, B. J., et al. (2013). Absolute quantification by droplet digital PCR versus analog real-time PCR. Nat. Methods 10, 1003-1005. doi: 10.1038/nmeth.2633

Hufnagel, R. B., Zimmerman, S. L., Krueger, L. A., Bender, P. L., Ahmed, Z. M., and Saal, H. M. (2016). A new frontonasal dysplasia syndrome associated with deletion of the SIX2 gene. Am. J. Med. Genet. Part A 170, 487-491. doi: 10.1002/ajmg.a.37441

Iwata, J., Tung, L., Urata, M., Hacia, J. G., Pelikan, R., Suzuki, A., et al. (2012). Fibroblast growth factor 9 (FGF9)-pituitary homeobox 2 (PITX2) pathway mediates transforming growth factor $\beta$ (TGF $\beta$ ) signaling to regulate cell proliferation in palatal mesenchyme during mouse palatogenesis. J. Biol. Chem. 287, 2353-2363. doi: 10.1074/jbc.M111.280974

Iyyanar, P. P. R., and Nazarali, A. J. (2017). Hoxa2 inhibits bone morphogenetic protein signaling during osteogenic differentiation of palatal mesenchyme. Front. Physiol. 8:929. doi: 10.3389/fphys.2017.00929

Kaufman, M. H. (1992). The Atlas of Mouse Development. New York, NY: AcademicPress.

Kawakami, K., Sato, S., Ozaki, H., and Ikeda, K. (2000). Six family genes-structure and function as transcription factors and their roles in development. BioEssays 22, 616-626. doi: 10.1002/1521-1878(200007)22:7<616::AID-BIES4>3.0.CO;2-R

Kutejova, E., Engist, B., Mallo, M., Kanzler, B., and Bobola, N. (2005). Hoxa2 downregulates Six 2 in the neural crest-derived mesenchyme. Development 132, 469-478. doi: 10.1242/dev.01536

Kutejova, E., Engist, B., Self, M., Oliver, G., Kirilenko, P., and Bobola, N. (2008). Six2 functions redundantly immediately downstream of Hoxa2. Development 135, 1463-1470. doi: 10.1242/dev.017624

Lan, Y., and Jiang, R. (2009). Sonic hedgehog signaling regulates reciprocal epithelial-mesenchymal interactions controlling palatal outgrowth. Development 136, 1387-1396. doi: 10.1242/dev.028167

Lan, Y., Ovitt, C. E., Cho, E.-S., Maltby, K. M., Wang, Q., and Jiang, R. (2004). Odd-skipped related 2 (Osr2) encodes a key intrinsic regulator of secondary palate growth and morphogenesis. Development 131, 3207-3216. doi: 10.1242/dev.01175

Lv, X., Mao, Z., Lyu, Z., Zhang, P., Zhan, A., Wang, J., et al. (2014). miR181c promotes apoptosis and suppresses proliferation of metanephric mesenchyme cells by targeting Six 2 in vitro. Cell Biochem. Funct. 32, 571-579. doi: 10.1002/cbf.3052

Lyu, Z., Mao, Z., Wang, H., Fang, Y., Chen, T., Wan, Q., et al. (2013). MiR-181b targets Six2 and inhibits the proliferation of metanephric mesenchymal cells in vitro. Biochem. Biophys. Res. Commun. 440, 495-501. doi: 10.1016/j.bbrc.2013.09.059

Matsumura, K., Taketomi, T., Yoshizaki, K., Arai, S., Sanui, T., Yoshiga, D., et al. (2011). Sprouty2 controls proliferation of palate mesenchymal cells via fibroblast growth factor signaling. Biochem. Biophys. Res. Commun. 404, 1076-1082. doi: 10.1016/j.bbrc.2010.12.116

McBratney, B. M., Margaryan, E., Ma, W., Urban, Z., and Lozanoff, S. (2003). Frontonasal dysplasia in $3 \mathrm{H} 1 \mathrm{Br} / \mathrm{Br}$ mice. Anat. Rec. A Discov. Mol. Cell. Evol. Biol. 271, 291-302. doi: 10.1002/ar.a.10034
Nazarali, A., Puthucode, R., Leung, V., Wolf, L., Hao, Z., and Yeung, J. (2000). Temporal and spatial expression of Hoxa-2 during murine palatogenesis. Cell. Mol. Neurobiol. 20, 269-290. doi: 10.1023/A:10070060 24407

Oliver, G., Wehr, R., Jenkins, N. A., Copeland, N. G., Cheyette, B. N., Hartenstein, V., et al. (1995). Homeobox genes and connective tissue patterning. Development 121, 693-705.

Rice, R., Spencer-dene, B., Connor, E. C., Gritli-linde, A., McMahon, A. P., Dickson, C., et al. (2004). Disruption of Fgf10 / Fgfr2b -coordinated epithelialmesenchymal interactions causes cleft palate. J. Clin. Invest. 113, 1692-1700. doi: 10.1172/JCI20384

Rijli, F. M., Mark, M., Lakkaraju, S., Dierich, A., Dollé, P., Chambon, P., et al. (1993). A homeotic transformation is generated in the rostral branchial region of the head by disruption of Hoxa-2, which acts as a selector gene. Cell 75, 1333-1349. doi: 10.1016/0092-8674(93) 90620-6

Self, M., Lagutin, O. V., Bowling, B., Hendrix, J., Cai, Y., Dressler, G. R., et al. (2006). Six2 is required for suppression of nephrogenesis and progenitor renewal in the developing kidney. EMBO J. 25, 5214-5228. doi: 10.1038/sj.emboj.7601381

Singh, G. D., Johnston, J., Ma, W., and Lozanoff, S. (1998). Cleft palate formation in fetal $\mathrm{Br}$ mice with midfacial retrusion: tenascin, fibronectin, laminin, and type IV collagen immunolocalization. Cleft Palate-Craniofacial J. 35, 65-76. doi: 10.1597/1545-1569(1998)035<0065:CPFIFB > 2.3.CO;2

Smith, T. M., Lozanoff, S., Iyyanar, P. P., and Nazarali, A. J. (2013). Molecular signaling along the anterior-posterior axis of early palate development. Front. Physiol. 3:488. doi: 10.3389/fphys.2012.00488

Smith, T. M., Wang, X., Zhang, W., Kulyk, W., and Nazarali, A. J. (2009). Hoxa2 plays a direct role in murine palate development. Dev. Dyn. 238, 2364-2373. doi: $10.1002 /$ dvdy. 22040

Thangaraj, M. P., Furber, K. L., Gan, J. K., Ji, S., Sobchishin, L., Doucette, J. R., et al. (2017). RNA binding protein Quaking stabilizes Sirt2 mRNA during oligodendroglial differentiation. J. Biol. Chem. 292, 5166-5182. doi: 10.1074/jbc.M117.775544

Vanderas, A. P. (1987). Incidence of cleft lip, cleft palate, and cleft lip and palate among races: a review. Cleft Palate J. 24, 216-225.

Wang, C. A., Drasin, D., Pham, C., Jedlicka, P., Zaberezhnyy, V., Guney, M., et al. (2014). Homeoprotein Six2 promotes breast cancer metastasis via transcriptional and epigenetic control of E-cadherin expression. Cancer Res. 74, 7357-7370. doi: 10.1158/0008-5472.CAN-14-0666

Welsh, I. C., and O'Brien, T. P. (2009). Signaling integration in the rugae growth zone directs sequential $\mathrm{SHH}$ signaling center formation during the rostral outgrowth of the palate. Dev. Biol. 336, 53-67. doi: 10.1016/j.ydbio.2009. 09.028

Welsh, I. C., Hagge-Greenberg, A., and O’Brien, T. P. (2007). A dosage-dependent role for Spry2 in growth and patterning during palate development. Mech. Dev. 124, 746-761. doi: 10.1016/j.mod.2007.06.007

Wu, W., Gu, S., Sun, C., He, W., Xie, X., Li, X., et al. (2015). Altered FGF signaling pathways impair cell proliferation and elevation of palate shelves. PLoS ONE 10, 1-17. doi: 10.1371/journal.pone.0136951

Xu, J., Liu, H., Lan, Y., Aronow, B. J., Kalinichenko, V. V., and Jiang, R. (2016). A Shh-Foxf-Fgf18-Shh molecular circuit regulating palate development. PLoS Genet. 12:e1005769. doi: 10.1371/journal.pgen.1005769

Zhou, J., Gao, Y., Lan, Y., Jia, S., and Jiang, R. (2013). Pax9 regulates a molecular network involving Bmp4, Fgf10, Shh signaling and the Osr2 transcription factor to control palate morphogenesis. Development 140, 4709-4718. doi: 10.1242/dev.099028

Conflict of Interest Statement: The authors declare that the research was conducted in the absence of any commercial or financial relationships that could be construed as a potential conflict of interest.

Copyright (c) 2017 Okello, Iyyanar, Kulyk, Smith, Lozanoff, Ji and Nazarali. This is an open-access article distributed under the terms of the Creative Commons Attribution License (CC BY). The use, distribution or reproduction in other forums is permitted, provided the original author(s) or licensor are credited and that the original publication in this journal is cited, in accordance with accepted academic practice. No use, distribution or reproduction is permitted which does not comply with these terms. 